\title{
Nursing managers attitude toward spirituality and spiritual care in Khorasan Razavi Province hospitals in 2016
}

\begin{abstract}
Ali Kavosi ${ }^{1}$, Mina Taghiabadi ${ }^{2}$, Gholamreza Mohammadi ${ }^{2}$, Khadijeh Yazdi $^{3}$, Sara Shirdelzadeh ${ }^{4}$, Hossein Nasiri $^{1}$, Ghanbar Roohi ${ }^{5}$, Alireza Shariati ${ }^{1}$, Hossein Rahmani ${ }^{1}$, Einollah Mollaei ${ }^{1}$, Mohammadreza Aryaeefar $^{6}$
\end{abstract}

${ }^{1}$ M.Sc. of Nursing, Faculty Member, Nursing Research Center, Golestan University of Medical Sciences, Gorgan, Iran

${ }^{2}$ M.Sc. of Nursing, Department of Operating Room, Faculty Member of Neyshabur University of Medical Sciences, Neyshabur, Iran

${ }^{3}$ Ph.D. of Nursing, Assistant Professor of Nursing, School of Nursing and Midwifery, Nursing Research Center, Golestan University of Medical Sciences, Golestan, Iran

${ }^{4}$ M.Sc. of Nursing, Department of Nursing, Faculty Member of Neyshabur University of Medical Sciences, Neyshabur, Iran

${ }^{5}$ M.Sc. of health services Management, Faculty Member, Nursing Instructor, Golestan University of Medical Sciences, Gorgan, Iran

${ }^{6}$ M.Sc. of Intensive Care Nursing, Department of Operating Room, Faculty Member of Neyshabur University of Medical Sciences, Neyshabur, Iran

Type of article: Original

\begin{abstract}
Background and aim: Spiritual care is an important part of nursing practice that seems to provide comprehensive care to patients. Nursing manager's attention to the spiritual dimension is one of the most important aspects affecting human health. Therefore, the aim of this study was to determine nursing managers' attitude to spirituality and spiritual care in hospitals in Khorasan Razavi Province in 2016.

Methods: In this cross-sectional study, 110 management nurses ( 8 matrons, 37 supervisors and 65 head nurses) of hospitals in Khorasan Razavi Province (2016) were recruited for the study. Data were collected using a Spirituality \& Spiritual Care Rating Scale (SSCRS) questionnaire in two parts, demographic information and questions related to the research objectives. Data were collected and analyzed using SPSS 16 software and doing descriptive (frequency, mean, standard deviation) and inferential statistics (independent-samples t-test, ANOVA) and considering levels of significance $(\mathrm{p}<0.05)$.

Results: The results showed mean and standard deviation in management nursing attitude to spirituality $(4.01 \pm 0.35)$ and spiritual care $(4.03 \pm 0.78)$. The result showed significant differences between the attitude to spirituality and spiritual care and gender, age and work experience in nursing management $(p<0.05)$.

Conclusions: Management nursing has high level attitude to spirituality and spiritual care. Therefore, providing the perfect platform to provide this care, and for nurses to implement it in hospitals is recommended.

Keywords: Attitude, Nursing, Spirituality, Nursing care
\end{abstract}

\section{Introduction}

Spirituality as an existential essence has received increasing attention in recent years because of its effect on human treatment and care (1). The World Health Organization defined health in four domains of physical, mental, social, and spiritual well-being, and emphasize on paying attention to patients' belief in care and communication. Thus, nurses can help patients' health protection as they provide comprehensive care (2). The Nurses International

\section{Corresponding author:}

Mohammadreza Aryaeefar, Department of Operating Room, Faculty Member of Neyshabur University of Medical Sciences, Neyshabur, Iran. Tel: +98.9150065246, Email: m.aryaee2012@gmail.com

Received: August 02, 2017, Accepted: November 21, 2017, Published: March 2018

iThenticate screening: November 20, 2017, English editing: December 12, 2017, Quality control: January 10, 2018

This article has been reviewed / commented by four experts

(C) 2018 The Authors. This is an open access article under the terms of the Creative Commons Attribution-NonCommercialNoDerivs License, which permits use and distribution in any medium, provided the original work is properly cited, the use is non-commercial and no modifications or adaptations are made. 
Association defined the role of nurses and nursing managers in environment promotion, in which spiritual values, habits and beliefs of individuals, families and society were respected (3). Also, nurses are expected, based on ethical codes of many universities, to care for patients based on their physical, mental, social, and spiritual needs and conditions. Therefore, spiritual education is necessary for holistic nursing care, and nurses should play an active role in meeting spiritual needs of patients (4). Recent studies strongly indicated that nursing managers and theoreticians paid special attention to spiritual powers as a need that gives unexplainable peace, power, and happiness to patients (5). Developing new methods of care and cure in recent years has proposed the need of establishing an effective and efficient frame work for the quality of care in the healthcare system (6). Spiritual caring (SC), as an important part of nursing (7), and has an effective role in obtaining the main goal of nurses and nursing managers, which are health improvement, disease prevention, health protection, and eliminating pain and discomfort (8). Recent studies have shown SC can improve the health and recovery of them. Also, the caring ability of health care professionals will improve by their increase in spiritual knowledge (9). SC along with other interventions can create a balance of physical, mental, and spiritual health and gain comprehensive health (10). Although attention and appropriate performance of patients' spiritual needs are one of nurses and nursing managers' duties (11); spiritual health of human beings has not received enough attention because of evidence shortage or low awareness of SC. Studies have shown that SC has not received enough attention because of different reasons including the ambiguous role of spirituality in caring, inappropriate relation between patients and healthcare professionals, environmental factors $(12,13)$, and improper attitude of nursing managers toward SC $(14)$. Hubbell et al. identified that $73 \%$ of nurses in California are inattentive to $\mathrm{SC}$ and didn't routinely apply it for their patients, and the improper attitude of managers to SC was one of the reasons (15). Despite appropriate spiritual awareness of nurses, its rare use in daily practice is revealed by Chung et al. who also showed the level of nurses' attitude toward spirituality was low because of indifference of some of the managers (16). It should be noted that there are studies that show the role of nursing managers in creating a positive attitude in nurses toward spirituality and spiritual care. For example, Mohammadi et al., in their study, concluded that attention to nursing managers toward spirituality with the implementation of educational programs in the field of spiritual care, has led to implementing spiritual care by the nurses at the patient's bedside (17). Also, Jafary et al. showed that the positive attitude of nurses in Kerman hospitals, to spiritual care was due to high attitude of nursing managers towards spirituality (18). Therefore, nursing managers' positive attitude and creating spiritual climate at their workplace leads to many benefits for their organization: such as creative personnel (that results in elevating the effectiveness of the organization), increase in validity and correctness of relationships, personal self-esteem and morale, job satisfaction and motivation, improvement and development, failure tolerance, decreased sensitivity to stress, and acceptance of demographic leadership (19-22). Hospital managers should pay special attention to the spiritual aspect of nursing care (23), as their attitude and beliefs have a direct effect on their behaviors; (23-25) and this subsequently has great effect on the function of groups (26). All decisions made in a hospital relate to managers, their tasks and opinions (27). Therefore, managers' attitude toward caring is one of the essential factors of its clinical implication. They are who decide about personnel duties, the way of doing tasks and nursing acts, etc. So, a positive managers' opinion about caring is a necessity for its clinical implication (14). Due to recent interest in spirituality in the healthcare system, and spiritual care as one of the essential duties of a healthcare team, especially nurses and nursing managers, researchers, with some reason, decided to assess the attitude of nursing managers toward spirituality and spirituality care. Reasons include: 1Iranians and Muslims being nursing managers and attention to the widespread, profound and historical role of spirituality in the existence of individual and all areas of the Iranian community, especially the healthcare system. 2The effect of nursing managers 'attitude on nurses' performance at patients' bedsides, according to the results of studies (15-18). 3- The lack of a similar study in nursing manager's category in Iran toward Spirituality and Spiritual Care.

\section{Material and Methods}

\subsection{Design and participants}

This was a cross-sectional study on 110 nursing managers ( 8 matrons, 37 supervisors, 65 head nurses) of 8 hospitals of Khorasan Razavi Province (hospitals in Mashhad and Nishapur city), who entered the study with census sampling (due to the limited number of nursing managers), during fall and winter, 2016. Inclusion criteria was having a BS degree and at least a 6-months management record of service. The exclusion criteria were lack of cooperation and unwillingness to participate.

\subsection{Data collection tools}

Data were gathered by demographic questionnaire and Spirituality and Spiritual Care Rating Scale (SSCRS) designed by Mc Sherry, Dropper, and Kendric in 2002 (26). It has 23 questions in two subscales of spirituality and 
spirituality care. The first subscale has 9 main domains including hope, meaning and goal, forgiveness, beliefs and values, relationships, belief in God, ethics, innovation, and self-report (the statements of 3, 4, 5, 6, 10, 11, 14, 15, 16, 17, 21, 22, and 23). The second subscale, spirituality care and interventions, involved listening, time spending, respect to patients' privacy and dignity, religious acts, and caring with attention and kindness (the statements of 1, 2, $7,8,9,12,13,18,19$, and 20). Scoring the questionnaire was with a 5-points Likert scale (completely disagree=with score 1 , disagree $=$ with score 2 , disagree, agree $=$ with score 3 , agree $=$ with score 4 , completely agree $=$ with score 5 ) . As a result, the mean score for each question was considered as one to five. Finally, after the total sum of the scores was obtained, their mean was taken. The mean between one and two represents negative and low attitude, the average between three and four represents positive and moderate attitude and the four-up average showed a positive and high attitude. The questionnaires were completed by the nursing managers by referring researchers in all parts of the hospital. This questionnaire's content validity and reliability $(\alpha=0.85$, and $r=0.83$ ) was examined by Mazaheri et al. (28). Also, its content validity was examined by 10 professors of Golestan University of Medical Sciences and Neyshabur University of Medical Sciences, and corrected based on their opinions. Test-retest method was used for assessing the reliability. The questionnaire was given to 10 samples and gathered after fulfilment, then re-completed by them after 2 weeks. They were $80 \%$ matched with each other.

\subsection{Ethical considerations}

At first, the objective of the study, confidentiality of fulfilling information, and anonymity of the questionnaire were demonstrated to participants by researchers, and the interested ones were entered into the study. Also, this article was approved with the code of ethics 12213 at Neyshabur University of Medical Sciences.

\subsection{Statistical analyses}

The reliable and validated questionnaire was given to all samples and analyzed by SPSS version 16, and descriptive (frequency, mean, standard deviation) and inferential statistics (Independent-samples t-test, ANOVA) was used. The confidence level was $95 \%(\mathrm{p}<0.05)$.

\section{Results}

Most of the managers were aged 30 to 40 years old (51.8\%) and had a record of service between 11 to 20 years (48.1\%). Other demographic data are shown in Table 1. Also, the analysis of demographic data and the total mean of SSCRS was done with independent t-test and one-way ANOVA. The independent-samples t-test revealed that there is significant difference between SSCRS score according to gender $(\mathrm{p}=0.048)$, and significant difference was seen according to age and record of service by one-way ANOVA ( $\mathrm{p}=0.033$ ) (Table 1). The analyses of SSCRS showed that the managers' attitude toward spirituality and spirituality care total was $4.02 \pm 0.98$ (Table 2).

Table 1. Demographic characteristics and difference between total score of SSCRS according to demographic data in nursing managers of Khorasan Razavi Province hospitals

\begin{tabular}{|c|c|c|c|c|}
\hline \multicolumn{2}{|l|}{ Demographic data } & $\mathrm{n}(\%)$ & Total score of SSCRS $($ Mean \pm SD) & p-values \\
\hline \multirow[t]{2}{*}{ Marriage status } & Single & $18(16.4 \%)$ & $3.99 \pm 0.63$ & \multirow{2}{*}{$\mathrm{p}=0.169$ (t-test) } \\
\hline & Married & $92(83.6 \%)$ & $4.08 \pm 0.82$ & \\
\hline \multirow[t]{3}{*}{ Age (years) } & $20-30$ & $15(13.7 \%)$ & $3.98 \pm 0.21$ & \multirow[t]{3}{*}{0.033 (ANOVA) } \\
\hline & $31-40$ & $57(51.8 \%)$ & $4.03 \pm 0.72$ & \\
\hline & $\geq 41$ & $38(34.5 \%)$ & $4.38 \pm 0.34$ & \\
\hline \multirow[t]{3}{*}{ Type of employment } & Official & $52(47.2 \%)$ & $4.07 \pm 0.83$ & \multirow[t]{3}{*}{0.816 (ANOVA) } \\
\hline & Contractual & $41(37.3 \%)$ & $4.05 \pm 0.51$ & \\
\hline & Conventional & $17(15.5 \%)$ & $4.03 \pm 0.94$ & \\
\hline \multirow[t]{2}{*}{ Gender } & Female & $68(60 \%)$ & $4.35 \pm 0.52$ & \multirow[t]{2}{*}{0.048 (t-test) } \\
\hline & Male & $42(40 \%)$ & $3.98 \pm 0.67$ & \\
\hline \multirow[t]{3}{*}{ Job title } & Head nurse & $65(59 \%)$ & $4.02 \pm 0.94$ & \multirow[t]{3}{*}{0.266 (ANOVA) } \\
\hline & Supervisor & $37(34 \%)$ & $4.17 \pm 0.78$ & \\
\hline & Matron & $8(7 \%)$ & $4.21 \pm 0.14$ & \\
\hline \multirow[t]{3}{*}{ work experience (years) } & $1-10$ & $21(19.1 \%)$ & $3.99 \pm 0.91$ & \multirow[t]{3}{*}{0.048 (ANOVA) } \\
\hline & $11-20$ & $53(48.1 \%)$ & $4.01 \pm 0.84$ & \\
\hline & $\geq 21$ & $36(32.7 \%)$ & $4.31 \pm 0.12$ & \\
\hline
\end{tabular}


Table 2. Mean and SD of nursing managers' attitude toward spirituality and spiritual care in Khorasan Razavi hospitals

\begin{tabular}{|c|c|c|c|c|}
\hline Dimensions of SSCRS & \multicolumn{4}{|c|}{ Job title $($ Mean \pm SD) } \\
\hline & Head nurse & Supervisor & Matron & Total \\
\hline Spirituality & $4.02 \pm 0.39$ & $3.98 \pm 0.34$ & $4.26 \pm 0.38$ & $4.02 \pm 0.98$ \\
\hline Spiritual care & $4.04 \pm 0.50$ & $4.18 \pm 0.49$ & $4.3 \pm 0.10$ & \\
\hline Spirituality and spiritual care & $4.03 \pm 0.41$ & $4.08 \pm 0.35$ & $4.28 \pm 0.11$ & \\
\hline
\end{tabular}

\section{Discussion}

The results showed mean and standard deviation in nursing managers' attitude to spirituality (4.01 \pm 0.35$)$ and spiritual care $(4.03 \pm 0.78)$ and the total was $(4.02 \pm 0.98)$. Wilson et al. identified that nursing managers of healthcare centers had appropriate attitude toward spirituality (29). Also, Battey et al. found appropriate spirituality in nursing managers (14). Other studies have confirmed our results, despite being carried out on nurses, like Mazaheri et al., Mauk and Schmidt, Shores et al., and Jafari et al. (18, 28, 30-32). According to religious structure of Iran, it was anticipated that the nursing managers have a positive attitude toward SC, however, do not use it in practice. Awareness and having a positive attitude toward SC is the first step of implementing it. One of the important affecting factor on nurses' attitude is the positive attitude of their managers (33). A spiritual manager pays attention to his her personnel spiritual beliefs and values, and increase their satisfaction and consequently induces sincere service and special care. Experiences showed spirituality in healthcare can result in the feeling of peace, tranquility, concentration, and conscientiously, care for patients, and also will flatten organizational ranks, and develop partnership sense in society (34). Of course, it should be noted that our study results are not consistent with Hubbell et al. and Chung et al. studies $(15,16)$. Perhaps the reasons for the inconsistency of the results are the difference in the time and number of participating managers, as well as differences in religion and the religion of nursing managers in studies. Nursing managers SSCRS score showed significant difference according to their age and record of service; the score of SSCRS was increased by elevating the age and work experience, which was in concordance with Mazaheri et al. (28), Vance et al. (11), and Landmark et al. (35). They reported a non-significant relationship between SSCRS and age, and record of service. But Boutell and Bozett reported significant relationship between SSCRS and age, and record of service (36). Perhaps the reason for the inconsistency of the results of the studies was the age difference and work experience in the participants and their classification in the studies, as well as the possible difference in the questionnaires used. Nevertheless, it can be explained that when the age of the individual increases, their attention to the religious dimension of life and spirituality increases. Considering that managers' performance is influenced by their attitude, it may be natural that as their age grows, their attention to spirituality becomes higher and their attitude towards this dimension will be more positive (8). Regarding the increase in the number of years of service, it can be said that nursing managers, especially head nurses with an increasing number of years of service, have experience of serving patients, different care and management conditions, and so perhaps reach the understanding that ignoring this dimension will have important effects on the health of patients and even nurses, and therefore experienced managers may have a more positive attitude and perspective on spiritual care (37). Significant relationship was found between spirituality and spirituality care and gender of managers. Female managers had more scores than males. Rahimi et al. (38), and Jafari et al. (30) have found the same relationship. It might be due to women's different characteristics and their compatibility with spiritual principals. In the explanation, it can be noted that spirituality and attitude towards spiritual care can exist in individuals, regardless of sex. However, there may be differences in performance and spiritual care are observed in female and male managers, but in general, there is no significant difference in their attitude due to the religious foundation of Iranian nursing managers. Also, our results have demonstrated non-significant relationship between spirituality and job title, which was in concordance with Battey et al. (14) and Fry et al. (39). This shows that all ranks of nursing managers besides different job characteristics, have the same attitude toward spirituality and spiritual care, which might be due to the attention to spirituality in all aspects of life in Islamic society of Iran; on the other hand, Iranian Muslim nursing managers' attitude toward SC is similar to that of Mazaheri et al. studies (28). The attitude of our samples was similar to other studies' samples with different religions and races. The fact becomes obvious that spirituality is above color, geographical frontiers, and other individual characteristics, and can unify an individual with others around the world, and God (40). It is hoped that in the future, considering the importance and place of spirituality and spiritual care, it will be taken into account in the field of care and treatment.

\section{Limitations}

The limitations of this research were the lack of similar internal and external articles, the small number of samples, the cross-sectional nature of the study, research done on a specific point in the country, not employing more valid 
methods of clinical assessment such as interviews, as well as mental and psychological conditions of nursing managers that have had an impact on answering questions. Therefore, it is suggested that for further studies, the research is done with a high number of samples and more reliable clinical assessment methods, and it is suggested that in future studies, nursing managers' attitudes should be compared with nurses.

\section{Conclusions}

Results have shown nursing managers of Khorasan Razavi Province hospitals had positive and high attitude toward spirituality and spirituality care. According to the profits of spirituality in organizations and high level of managers' attitude to it, it can provide appropriate clinical conditions for nurses. Also, the attention of nursing and midwifery schools, their managers, planners, and instructors to edit operational programs for spirituality care in hospital is essential.

\section{Acknowledgments:}

We wish to thank all the nursing managers of Khorasan Razavi Province hospital for their cooperation throughout the survey. We also appreciate Fereshteh Mirshahi, and Azam Moghaddam Pasha for his valuable collaboration in the field of data collection.

\section{Conflict of Interest:}

There is no conflict of interest to be declared.

Authors' contributions:

All authors contributed to this project and article equally. All authors read and approved the final manuscript.

\section{References:}

1) Markani AK, Fard MK, Yaghmaei F, Abbasi M, Didarloo A. Spirituality as Experienced by Iranian Muslim Oncology Nurses; A qualitative study. History of Medicine Journal. 2015; 6(21): 185-209.

2) Baldacchino DR. Teaching on the spiritual dimension in care to undergraduate nursing students: The content and teaching methods. Nurse Educ Today. 2008; 28(5): 550-62. doi: 10.1016/j.nedt.2007.09.003. PMID: 17950959.

3) Sanders L, Kopis S, Moen C, Pobanz A, Volk F. Perceptions of spirituality and spiritual care in religious nurses. J Christ Nurs. 2016; 33(4): 214-9. doi: 10.1097/CNJ.0000000000000308. PMID: 27610904.

4) Van Leeuwen R, Tiesinga LJ, Post D, Jochemsen H. Spiritual care: implications for nurses' professional responsibility. J Clin Nurs. 2006; 15(7): 875-84. doi: 10.1111/j.1365-2702.2006.01615.x. PMID: 16879380.

5) Movaghari M, Nikbakht NA. An investigation into the quality of spiritual rehabilitation in hospitalized elderly patients in mental ward. Payesh. 2003; 2(2): 121-26.

6) Agarwal R, Kalita J, Misra U. Barriers to evidence-based medicine practice in South Asia and possible solutions. Neurology Asia. 2008; 13(3): 87-94.

7) Farahaninia M, Abbasi M, Givari A, Haghani H. Nursing students' spiritual well-being and their perspectives towards spirituality and spiritual care perspectives. Iran Journal of Nursing. 2006; 18(44): 7 14.

8) Lavasani M, Keyvanzade M, Arjmand N. Spirituality, job stress, organizational commitment, and job satisfaction among nurses in Tehran. J Contemporary Psychology. 2009; 2(3): 61-73.

9) Yang KP. The spiritual intelligence of nurses in Taiwan. J Nurs Res. 2006; 14(1): 24-35. doi: 10.1097/01.JNR.0000387559.26694.0b. PMID: 16547903.

10) Andrews MM, Boyle JS. Transcultural concepts in nursing care. Lippincott Williams \& Wilkins; 2008.

11) Vance DL. Nurses' attitudes towards spirituality and patient care. Med Surg Nursing. 2001; 10(5): 264.

12) Narayanasamy A, Owens J. A critical incident study of nurses' responses to the spiritual needs of their patients. J Adv Nurs. 2001; 33(4): 446-55. doi: 10.1046/j.1365-2648.2001.01690.x. PMID: 11251732.

13) Wong KF, Yau SY. Nurses' experiences in spirituality and spiritual care in Hong Kong. Appl Nurs Res. 2010; 23(4): 242-4. doi: 10.1016/j.apnr.2008.10.002. PMID: 21035036.

14) Battey BW. Perspectives of spiritual care for nurse managers. J Nurs Manag. 2012; 20(8): 1012-20. doi: 10.1111/j.1365-2834.2012.01360.x. PMID: 23151103.

15) Hubbell SL, Woodard EK, Barksdale - Brown DJ, Parker JS. Spiritual care practices of nurse practitioners in federally designated nonmetropolitan areas of North Carolina. J Am Acad Nurse Pract. 2006; 18(8): 379 85. doi: 10.1111/j.1745-7599.2006.00151.x. PMID: 16907700. 
16) Chung LY, Wong FK, Chan MF. Relationship of nurses' spirituality to their understanding and practice of spiritual care. J Adv Nurs. 2007; 58(2): 158-70. doi: 10.1111/j.1365-2648.2007.04225.x. PMID: 17445019.

17) Mohammadi G, Mirshahi F, Movahedi A, Taghavi M, Pasha AM, Mardani M, et al. Nurses and midwives attitude of hospitals of Neyshabur city about spirituality and spiritual care. Medical Ethics Journal. 2015; 9(33): 45-63.

18) Jafari M, Sabzevari S, Borhani F. View nurses and nurse student of kerman university of Medical Sciences to spiritual care. Journal of Medical Figh. 2012; 6(20): 155-71.

19) Ghorbanian A, Bahadori M, Nejati M. The relationship between managers' leadership styles and emergency medical technicians' job satisfaction. Australas Med J. 2012; 5(1): 1-7. doi: 10.4066/AMJ.2011892. PMID: 22905048 , PMCID: PMC3413924.

20) Karakas F. Spirituality and performance in organizations: A literature review. Journal of business ethics. 2010; 94(1): 89-106. doi: 10.1007/s10551-009-0251-5.

21) Marschke EB. A comparative study: Do corporations that embrace spirituality in the workplace encourage desired organizational outcomes? Nova Southeastern University; 2008.

22) Van der Walt F, de Klerk JJ. Workplace spirituality and job satisfaction. Int Rev Psychiatry. 2014; 26(3): 379-89. doi: 10.3109/09540261.2014.908826. PMID: 24953156.

23) Shojaie P, Sadeghi T, Karimi T, Mokhtari P. The relationship between manager's spirituality and spirituality at work with staff and patients satisfaction in Qazvin University of Medical Sciences. Payesh. 2012; 11(4): 451-8.

24) Currie J, Fahr J. Hospitals, managed care, and the charity caseload in California. J Health Econ. 2004; 23(3): 421-42. doi: 10.1016/j.jhealeco.2001.11.001. PMID: 15120464.

25) Kirsten W. Health and productivity management in Europe. International journal of workplace health management. 2008; 1(2): 136-44. doi: 10.1108/17538350810893928.

26) Suhonen R, Stolt M, Virtanen H, Leino-Kilpi H. Organizational ethics: a literature review. Nurs Ethics. 2011; 18(3): 285-303. doi: 10.1177/0969733011401123. PMID: 21558106.

27) Hemmati Maslakpak M, Habib Zadeh H, Khalil zadeh H. Managers and nurses function of safe patients' care from the nurses Perspective. Health Promotion Management. 2012; 1(2): 7-14.

28) Mazaheri M, Fallahi Khoshknab M, Bagher Maddah S, Rahgozar M. Nursing attitude to spirituality and spiritual care. Payesh. 2009; 8(1): 31-7.

29) Wilson CL. A relational study of leadership spirituality and organizational performance in home health care agencies. University of Phoenix; 2008.

30) Jafari E, Dehshiri GR, Eskandari H, Najafi M, Heshmati R, Hoseinifar J. Spiritual well-being and mental health in university students. Procedia-Social and Behavioral Sciences. 2010; 5: 1477-81. doi: 10.1016/j.sbspro.2010.07.311.

31) Shores CI. Spiritual perspectives of nursing students. Nurs Educ Perspect. 2010; 31(1): 8-11. PMID: 20397473.

32) Mauk KL, Schmidt NA. Spiritual care in nursing practice. Lippincott Williams \& Wilkins; 2004.

33) Tofighian T, Kooshki A, Borhani F, Rakhshani MH, Mohsenpour M. Nursing students and nurses attitude toward spirituality and spiritual care. History of Medicine Journal. 2017; 8(29): 45-62.

34) Khorashadizadeh F, Ahanchian M. Explorating spiritual management in nursing: a hermeneutic phenomenological. Nursing Management. 2015; 4(1): 49-60.

35) Lundmark M. Attitudes to spiritual care among nursing staff in a Swedish oncology clinic. J Clin Nurs. 2006; 15(7): 863-74. doi: 10.1111/j.1365-2702.2006.01189.x. PMID: 16879379.

36) Boutell KA, Bozett FW. Nurses' assessment of patients' spirituality: Continuing education implications. J Contin Educ Nurs. 1990; 21(4): 172-6. PMID: 2116464.

37) Salmani D, Moinian N. The relation between spirituality and leadership. Cultural Engineering. 2009; 45\&6: 47-54.

38) Rahimi N, Nouhi E, Nakhaee N. Spiritual Well-being and Attitude toward Spirituality and Spiritual Care in Nursing and Midwifery Students. Iran Journal of Nursing. 2013; 26(85): 55-65.

39) Fry LW, Matherly LL. Spiritual leadership and organizational performance: An exploratory study. Tarleton State University-Central Texas. 2006.

40) Zakeri A, Hoveida R, Najafi M. Spiritual leadership with Islamic approach. Islamic Research. 2012; 2(4): 25-36. 